\title{
Assessment of bacteriophage activity against local strains of Enterococcus and Pseudomonas in Romania
}

\author{
Alina Cristina Neguț ${ }^{1,2 *}$, Oana Săndulescu ${ }^{1,2}$, Anca Streinu-Cercel ${ }^{1,2}$, Zemphira Alavidze ${ }^{3}$, loana Berciu ${ }^{1,2}$, \\ Veronica $\| i^{2}$, Magdalena Lorena Andrei ${ }^{2}$, Dana Mărculescu², Mircea loan Popa ${ }^{1}$, Adrian Streinu-Cercel ${ }^{1,2}$ \\ From The 10th Edition of the Scientific Days of the National Institute for Infectious Diseases "Prof Dr Matei \\ Bals" \\ Bucharest, Romania. 15-17 October 2014
}

\section{Background}

Enterococcus faecium and Pseudomonas aeruginosa are part of the ESCAPE pathogens, which have the ability to "escape" the currently available therapeutic options. For these germs alternatives are needed, as is the case of bacteriophage treatment.

\section{Methods}

In this study we used a bacteriophage testing kit containing 4 types of Georgian products: PYO, INTESTI (Eliava BioPreparations, Tbilisi) and PHAGYO, PHAGESTI (JSC "Biochimpharm", Tbilisi) to test the strains of Pseudomonas spp. and Enterococcus spp. isolated and stored from patients treated in the Adults II ward of the National Institute for Infectious Diseases "Prof. Dr. Matei Balş", Romania during April 2013 - July 2014.

\section{Results}

We identified 9 strains of Enterococcus (7 E. faecalis, 1 E. avium and 1 E. faecium) and 9 strains of Pseudomonas aeruginosa. The strains had been isolated mostly from cutaneous wounds (3/9) for Enterococcus spp. and from urine (5/9) for P. aeruginosa. For Enterococcus spp. the rate of susceptibility to PYO phages was $33.33 \%$ (3/9), to INTESTI 55.56\% (5/9), to PHAGYO $44.44 \%$ (4/9) and to PHAGESTI 0\% (0/9). We tested the Enterococcus ATTC, and it displayed susceptibility to PYO, INTESTI and PHAGYO.
For Pseudomonas spp. the rate of susceptibility to PYO phages was of $66.67 \%$ (6/9), INTESTI 88.89\% (8/9), PHAGYO 55.56\% (5/9), PHAGESTI 44.44\% (4/9). We tested the Pseudomonas ATTC, and it displayed susceptibility to all the bacteriophage products tested.

Performing the ANOVA test for Enterococcus spp. we identified a statistically significant correlation between susceptibility to ampicillin vs. PYO phages $(\mathrm{p}=0.034)$ and vs. INTESTI phages $(\mathrm{p}=0.024)$. For $P$. aeruginosa a correlation was identified between susceptibility to ceftazidime and PYO phages $(\mathrm{p}=0.029)$.

\section{Conclusion}

Despite the fact that PYO and PHAGYO do not contain phages for Enterococcus spp., their activity against it was similar to that of INTESTI. PYO and PHAGYO showed activity on Enterococcus ATCC, too. For P. aeruginosa the rate of susceptibility was very high for phages, and quite low for almost all antibiotics tested. We intend to develop further studies for testing a higher number of strains and for assessing a potential synergy for co-administration of antibiotics and bacteriophages.

\footnotetext{
Acknowledgements

1. This paper is partly supported by the Sectorial Operational Programme Human Resources Development (SOPHRD), financed by the European Social Fund and the Romanian Government under the contract number POSDRU 141531.

2. This paper is partly supported by the Carol Davila University of Medicine and Pharmacy, Young Researchers Grant, no 28341/2013.
}

* Correspondence: negoitza_alina@yahoo.com

${ }^{1}$ Carol Davila University of Medicine and Pharmacy, Bucharest, Romania

Full list of author information is available at the end of the article 


\section{Authors' details}

${ }^{1}$ Carol Davila University of Medicine and Pharmacy, Bucharest, Romania.

${ }^{2}$ National Institute for Infectious Diseases "Prof. Dr. Matei Balş", Bucharest,

Romania. ${ }^{3}$ Phage Therapy Center Tbilisi, Georgia.

Published: 15 October 2014

doi:10.1186/1471-2334-14-S7-019

Cite this article as: Negut et al.: Assessment of bacteriophage activity

against local strains of Enterococcus and Pseudomonas in Romania. BMC

Infectious Diseases 2014 14(Suppl 7):O19.

Submit your next manuscript to BioMed Central and take full advantage of:

- Convenient online submission

- Thorough peer review

- No space constraints or color figure charges

- Immediate publication on acceptance

- Inclusion in PubMed, CAS, Scopus and Google Scholar

- Research which is freely available for redistribution

Submit your manuscript at 